\title{
Differential effects of diazepam and lorazepam on repetition priming in healthy volunteers
}

\author{
François Sellal ${ }^{1}$, Jean-Marie Danion ${ }^{2}$, Françoise Kauffmann-Muller ${ }^{2}$, Danielle Grangé ${ }^{3}$, Jean-Louis Imbs ${ }^{4}$, \\ Martial Van Der Linden ${ }^{5}$, and Léonard Singer ${ }^{2}$ \\ ${ }^{1}$ Clinique Neurologique, Service de Neurologie I, Hôpitaux Universitaires, F-67091 Strasbourg Cedex, France \\ 2 Département de Psychiatrie, Hôpitaux Universitaires, F-67091 Strasbourg Cedex, France \\ ${ }^{3}$ Centre de Calcul, C.N.R.S., 23, rue du Loess, F-67200 Strasbourg, France \\ 4 Institut de Pharmacologie, Unité de Pharmacologie Clinique, Faculté de Médecine, 11 rue Humann, F-67000 Strasbourg, France \\ ${ }^{5}$ Unité de Neuropsychologie Cognitive, Université de Louvain, Faculté de Psychologie, Voie du Roman Pays, 20, \\ B-1348 Louvain La Neuve, Belgium
}

Received November 11, 1991 / Final version February 26, 1992

\begin{abstract}
The effects of two benzodiazepines, diazepam (15 or $20 \mathrm{mg}$ orally) and lorazepam (1.75 or $2.5 \mathrm{mg}$ orally), and a placebo on explicit memory, lexical priming and perceptual priming were assessed using a freerecall, a word-completion and a picture-completion test. The picture-completion test included two different study conditions intended to manipulate the magnitude of the priming effect. Sixty healthy volunteers took part in this double-blind study. Free-recall performances were altered by both drugs. Lorazepam impaired wordcompletion and picture-completion performance, whereas diazepam only exhibited a deleterious effect on the more sensitive of the two measures of the picturecompletion test. These results indicate that the two benzodiazepines have differential amnestic effects. It is suggested that these differential effects could be accounted for by a different cortical distribution of the two benzodiazepines.
\end{abstract}

Key words: Benzodiazepines - Diazepam - Human Lorazepam - Memory - Repetition priming

Soon after their introduction as a treatment for anxiety, it appeared that benzodiazepines had an amnestic effect (Brandt and Oakes 1965; Brown and Dundee 1968; Clarke et al. 1970). Subsequent studies demonstrated that anterograde amnesia following benzodiazepine administration resulted from an impairment in acquisition of new information whereas access to information acquired before drug administration was intact (Clarke et al. 1970; Ghoneim and Mewaldt 1975; Clark et al. 1979; Brown et al. 1982). These studies of benzodiazepineinduced amnesia were carried out using free-recall, cuedrecall and recognition tests. In such tests, subjects are explicitly asked to try to remember recently presented information. Thus, Graf and Schacter (1985) labelled the memory assessed by these traditional tests explicit memory.

Offprint requests to: J.-M. Danion
Recently, attention has been given to experimental situations in which a previously encoded information is subsequently expressed without any conscious recollection. This memory is referred to as implicit because instructions refer only to the task in hand and never to a previous learning episode. Implicit memory is revealed by an improvement in task performance which is attributable to information acquired during a prior study episode. In the word-stem completion test, subjects are shown a list of words which includes, for instance, the word DEFENCE; a few minutes later they are required to complete a list of word stems (i.e. DEF...) with instruction to write the first word that comes to mind. Subjects show an enhanced tendency to complete stems by forming a word presented in the study list (here DEFENCE rather than DEFECT, for instance). Such a phenomenon is referred to as repetition priming. The word-completion task explores lexical priming but a priming effect can be observed in a large variety of implicit memory tests, using different material. This is the case for the picture-fragment completion task, which provides evidence of a perceptual priming effect. In this task, subjects are first shown a series of line drawings of common objects, such as a comb or stool, which they are asked to identify. Later, they are presented with a series of increasingly more complete line drawings, including pictures presented in the study phase (old pictures) and others that were not (new pictures), until they can identify them. Subjects perform better with old pictures than with new pictures. This savings in picture-identification performance is a measure of implicit memory because subjects are never required to retrieve information consciously from the study phase to show perceptual priming.

Explicit and implicit memory are distinct and separable forms of memory, as is suggested by several lines of evidence (review in Richardson-Klavehn and Bjork 1988), the foremost stemming from patients with organic amnesia. While displaying profound impairment in explicit memory tests, these patients demonstrate spared capacities in many priming tasks (Warrington and 
Weiskrantz 1970; Graf et al. 1984; Cermak et al. 1985; Moscovitch et al. 1986). More recently, a similar dissociation has been identified in benzodiazepine-induced amnesia: diazepam-treated subjects exhibit normal word-completion performance but are impaired in a freerecall test (Fang et al. 1987; Danion et al. 1989, 1990).

It is classically admitted that the amnestic effect of the different benzodiazepines is qualitatively similar. Amnesia would thus only differ from one drug to an other in terms of magnitude, time of onset and duration and would be a function of the drug, the dose, the route of administration and the population of subjects to which the benzodiazepines are administered (Lister 1985). It has recently been reported that lorazepam, another benzodiazepine, impaired both explicit memory and repetition priming, as assessed by a word-completion task (Brown et al. 1989; Curran 1991; Danion et al. 1992). These apparently discrepant results might reflect a qualitative difference between the two benzodiazepines, (Lister 1991) but caution is needed in interpretating these results in the absence of a direct comparison between these two benzodiazepines; in addition, their effects on other priming tasks have not yet been investigated. The aim of this study was to compare directly the effects of diazepam and lorazepam on explicit memory and repetition priming in healthy volunteers. To determine whether the hypothetized differences between the two benzodiazepines are task-dependent or reflect true differential effects on repetition priming, two implicit memory tasks were used: a word-completion task, assessing lexical priming, and a picture-completion task, assessing perceptual priming. Although Tulving and Schacter (1990) have proposed that these two forms of priming are expressions of a single perceptual representation system, their dissociation in Alzheimer's disease suggests that word completion and picture completion involve distinct cognitive processes (Keane et al. 1991).

\section{Materials and methods}

\section{Subjects}

Sixty paid healthy volunteers of both sexes whose native language was French were recruited from the University of Strasbourg. They all studied medicine and ranged in age from 20 to 29 (mean age: $22.4, \mathrm{SD}=2.4$ ). The subjects had no medical illness or history of alcoholism, drug abuse or tobacco consumption of more than 10 cigarettes/day. They were not chronic users of benzodiazepines and had not taken any concomitant medication for at least 15 days. They were instructed to abstain from beverages containing caffein or alcohol for the $24 \mathrm{~h}$ prior to the study. All subjects were tested in the morning, after an overnight fast. The protocol was approved by the Faculty Ethics Committee. All the volunteers gave their written informed consent.

\section{Experimental design and drugs}

Subjects were randomly assigned to one of 5 parallel groups, each of 12 subjects: a placebo group, a diazepam $15 \mathrm{mg}$ group, a diazepam $20 \mathrm{mg}$ group, a lorazepam $1.75 \mathrm{mg}$ group and a lorazepam $2.5 \mathrm{mg}$ group. Thus, for each drug a low and a high amnesia-inducing dose was selected on the basis of an equipotential effect on explicit memory. According to Dundee et al. (1979), the amnesic potency of lorazepam would be 5 times that of the diazepam, although Kothary et al. (1981) thought that the ratio was 1:10. On the basis of our previous studies and these data, we chose doses compatible with commercially available tablets at intermediate ratios that were roughly equivalent for the low and high doses $(1: 8.6$ and $1: 8$, respectively).

The duration of explicit memory impairment is greater for lorazepam than for diazepam. Nevertheless, the chosen doses of diazepam induced a marked amnestic effect throughout the duration of the study (Ghoneim et al. 1984). Peak plasma concentrations are usually attained within $60 \mathrm{~min}$ for diazepam and $120 \mathrm{~min}$ for lorazepam, after oral administration (Mandelli et al. 1978; Ameer and Greenblatt 1981). To test subjects during the peak concentration, the drugs were administered as follows: subjects from diazepam groups received a placebo at 8 a.m. and diazepam (either 15 or $20 \mathrm{mg}$ ) at 9 a.m. Subjects from lorazepam groups received lorazepam (either 1.75 or $2.5 \mathrm{mg}$ ) at 8 a.m. and a placebo at 9 a.m. and subjects from the placebo group received twice a placebo, at 8 and 9 a.m. A double-blind procedure was followed.

\section{Tests}

A series of memory and cognition tests were administered to each subject individually. Implicit memory was assessed by a word-stem completion task and a picture-fragment completion task, and explicit memory by a free-recall task. Semantic memory, short-term memory and ability to process visual information were assessed by verbal generation tasks, digit span task and Gottschaldt's hidden figures task, respectively. Subjects assessed their subjective state of sedation with visual analogue scales. Testing began at 10 a.m. for all subjects and lasted approximately $80 \mathrm{~min}$. The order of the tests and their respective times of administration are summarized in Table 1.

\section{Implicit memory}

Word completion task. This was designed to assess the lexical priming effect. A pool of 60 target words, consisting of common words, was selected according to the following criteria. First, the initial three letters - the stem - of each word had to be unique in the whole set of words. Second, for each three-letter target stem, a French pocket dictionary had to list at least ten common words with the same stem, thus ensuring that subjects would be easily able to generate a completion for each stem. Third, the target words had to have at least five letters and had to be of medium frequency (range 40-70 per million, according to the Frequency Dictionary of

Table 1. Schedule of testing

\begin{tabular}{ll}
\hline 0800 & Ingestion of lorazepam or placebo \\
0900 & Ingestion of diazepam or placebo \\
1000 & Picture-fragment completion task: study phase \\
& Digit span task \\
& Word-completion task: study phase \\
& Category- and letter-generation tasks \\
& Word-completion task: test phase \\
& Free-recall task \\
& Digit symbol substitution task \\
& Gottschaldt's hidden figures task \\
& Visual analogue scales \\
& Picture-fragment completion task: test phase \\
1100 & Questionnaire of awareness \\
&
\end{tabular}


French Words, Juilland et al. 1970). The pool of 60 target words was then randomly divided into two sets of words.

Subjects were shown a list of 36 words: the 30 target words with 3 buffer words at the beginning and the end of the set, to control primacy and recency effects. The words were typed on an index card, and subjects were instructed to try to remember them. Subjects were given $5 \mathrm{~s}$ to read each word aloud and rate it on a visual analogue scale according to how much the word was liked or disliked. After studying the list of 36 words, subjects underwent a 6 min distractor task, followed by the completion test. The completion test form listed all 60 target word stems: the stems of the 30 words presented in the study phase (primed words or "old words") were randomized with the 30 non-presented words of the other set (non-primed words or "new words"). Thus, half the test items measured completion on previously presented words and the other half provided a measure of baseline or chance performance. The two sets were counterbalanced across subjects. The completion test was administered with instructions to complete each stem with the first word which came to mind, working quickly. When a proper name was generated, the experimenter asked for an alternative completion.

Picture-fragment completion task. It was intented to assess perceptual priming. Three sets of seven pictures of objects were drawn from a pool of 150 pictures selected from Snodgrass et al. (1987). For each picture, a series of fragmented images at eight levels of fragmentation was obtained, using an algorithm which randomly and cumulatively deleted equal blocks from the picture to produce 8 levels of fragmentation per stimulus (Snodgrass et al. 1987). Level 1 corresponded to the most fragmented picture and level 8 to the complete picture. For a given level, the degree of fragmentation was comparable between the different pictures.

The task comprised two different study conditions. In one condition (complete condition), pictures were shown complete (level 8). In the other study condition (fragmented condition), a series of increasingly more complete pictures were shown until they were identified; this condition produces more savings on subsequent identification performance (Snodgrass and Feenan 1990). The enhancement of savings could be explained by the experience of perceptual closure at study, consisting of filling in gaps in the contours of fragmented pictures so as to perceive the pictures (Snodgrass and Feenan 1990). This experience supposedly reorganizes the processes of perceiving the pictures, which can therefore be identified at test with less information, i.e. at a higher level of fragmentation. The inclusion of a fragmented condition in this study was based on the assumption that the experience of perceptual closure would exacerbate the processes underlying perceptual priming, and was therefore intended to maximize the deleterious effects of the drugs.

Subjects were told that they would have to identify pictures that were shown on an index card. They were presented with two randomly mixed sets of seven pictures. Pictures from one set were shown complete, each one for $10 \mathrm{~s}$. Those from the other set were shown at level 1, and subjects were asked to identify the fragmented picture within $5 \mathrm{~s}$; if they failed, subjects were shown the next level of fragmentation, until they were successful, according to the ascending method of limits. The two sets were counterbalanced across subjects. Three practice pictures, common to both sets, preceded the presentation of the 14 pictures and were not scored. After a delay of $1 \mathrm{~h}$, during which they performed other tasks, subjects underwent the completion test. They were shown 21 pictures, including the 14 study pictures (old pictures) and 7 new pictures. Each series of fragmented pictures was shown with the ascending method of limits, in which the most fragmented picture (level 1) was presented first. Subjects had $5 \mathrm{~s}$ to identify the picture at a given level. The perceptual identification threshold was the level of fragmentation (levels $1-8)$ at which the picture was identified.

The data of interest were the identification thresholds of the old and new pictures during the test phase. Savings was calculated for each of the two study conditions by subtracting identification thresholds of new pictures from those of old pictures.

\section{Explicit memory}

The recall test was administered after the word-completion task, with the instruction to retrieve as many words from the study list as possible in $3 \mathrm{~min}$.

\section{Short-term memory}

This memory was assessed using the digit span from the WAIS-R (1981). In addition a digit symbol substitution test was carried out for $90 \mathrm{~s}$ (WAIS-R).

\section{Semantic memory}

In this task, subjects were required to write, in $90 \mathrm{~s}$, as many words as they could from a given category (four-footed animal) and a given letter (French words beginning with the letter W).

\section{Gottschaldt's hidden figures test}

This test was intended to assess ability to process visual information. It used 34 simple figures and 34 relatively complex geometrical figures in which the former were hidden. Subjects were required to identify each hidden figure by tracing the outline of the simple figure embedded in the more complex one (Gottschaldt 1928). The subjects' performance was assessed according to the accuracy of the drawings (number of the 34 hidden figures correctly outlined) and the time required to perform the task.

\section{Analogue self-ratings}

At the end of the study, subjects used a set of 15 visual analogue scales to assess their subjective state. Each scale consisted of a $100 \mathrm{~mm}$ horizontal line without gradation, anchored by contrasting states of mind. Subjects were told to indicate how they felt at the moment by placing a mark along this continuum. The scales were scored by measuring the distance in millimeters of the mark from the left end of the line. Five of these scales assessed complementary aspects of sedation (alert-drowsy, excited-calm, clear headedmuzzy, energic-lethargic, quick-slow); the mean score of these five scales was calculated for each subject and was taken as a measure of sedation.

\section{Awareness questionnaire}

At the end of the study, once all the memory tests had been carried out, subjects were submitted a questionnaire, designed to investigate the relationship between performance in implicit tasks and awareness/unawareness of the study episode during the testing phase. Based on Bowers and Schacter (1990), the questionnaire included four questions, which were adapted for each implicit task, i.e. word-completion and picture-completion task. Two questions were more open-ended: i) "What did you think was the purpose of the task?"; ii) "What was your strategy in completing the word stems (or identifying the fragmented pictures)?" The two last questions were more pointed: i) "Did you notice any relationship between the list of words you read at the start of the study and the words produced in completing the stems?" or "Did you notice any relationship between the pictures presented at the start of the study and those you had to identify at the end?"; ii) "While completing the stems, did you notice whether you were completing some of the stems with the words shown earlier?" or "While completing the picture-fragments, did you notice whether some identified pictures were the same as those shown earlier?". Subjects who did not mention the existence of a study episode in response to the two 
former questions and responded negatively to the two last questions were categorized as test unaware.

\section{Statistical analysis}

The results were analysed with an analysis of variance. Whenever this analysis was significant, $t$-tests were used to compare performances between groups; the $P$ values were corrected according to the Bonferroni probabilities. Analyses of covariance (ANCOVAs) were carried out on word- and picture-completion performance using free-recall, digit symbol substitution and Gottschaldt's test performance, and self-ratings of sedation as covariates, according to Cochran and Cox (1957). The stochastic dependence between word-completion and free-recall tests in each group was studied using the chi ${ }^{2}$ method as suggested by Tulving et al. (1982); the basic statistical unit of this analysis was a subject-item.

\section{Results}

The five groups did not significantly differ in terms of mean age, mean weight and mean score on the Wechsler Memory Scale, measured during a prestudy session [placebo: $118.9 \pm 4.1$; diazepam $15 \mathrm{mg}: 115.4 \pm 3.5$; diazepam $20 \mathrm{mg}$ : $116.6 \pm 4.0$; lorazepam $1.75 \mathrm{mg}$ : $114.6 \pm 3.8$ : lorazepam $2.5 \mathrm{mg}: 115.0 \pm 4.6 ; F(4.55)=2.28, \mathrm{NS}]$.

\section{Free-recall and word-completion tasks}

The mean free-recall and word-completion performances are shown in Table 2 and in Fig. 1. As expected, a significant drug effect was found in the free-recall task $[F(4,55)=8.42, P<0.0001]$, diazepam and lorazepam provoking a significant impairment of free-recall performances. The deficit was more pronounced with the highest doses of the drugs, but there was no significant differences between the four active groups.

In the word-completion task, the number of new words successfully completed, i.e., baseline performance, did not vary significantly across groups $[F(4,55)=2.22]$. There was a significant drug effect on lexical priming as measured by the number of old words successfully completed $[F(4,55)=6.36, P<0.0001]$. Lorazepam, but not

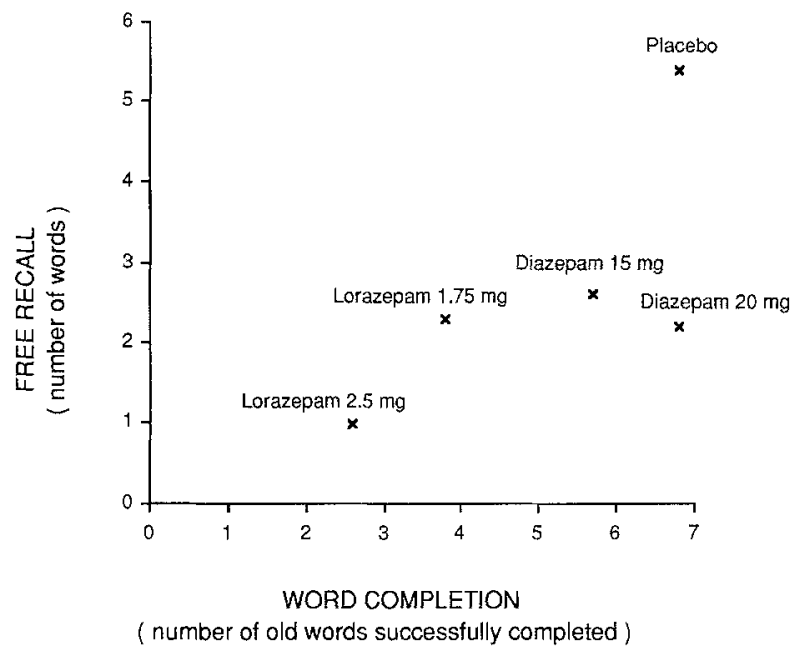

Fig. 1. Mean free-recall performance as a function of mean wordcompletion performance in the 5 groups

diazepam, decreased the number of old words successfully completed, the deficit being significant at the $2.5 \mathrm{mg}$ dose; this indicated that the two benzodiazepines have differential effects. The analysis of implicit performance, expressed as the number of old words successfully completed by each subject minus the number of new ones, yielded a similar conclusion. An ANOVA revealed a significant drug effect $[F(4,55)=2.92, P<0.05]$, follow-up analyses indicating that lorazepam $2.5 \mathrm{mg}$ induced a significant deficit of implicit performance. However, the differential effects of the two drugs were less clear-cut, a slight, non-significant decrease in performance being observed in the diazepam groups; this was due to a non-significant increase in the number of new words successfully completed (baseline performance) by the diazepam-treated subjects.

Free-recall and word-completion performances were not significantly correlated. In addition, a contingency table comparing word completion and free recall showed that the number of words recalled was higher than expected when the words had previously been completed successfully in the placebo $(P<0.0001$, Fisher's exact
Table 2. Effects of diazepam, lorazepam and placebo on free-recall and wordcompletion performance

\begin{tabular}{|c|c|c|c|c|c|}
\hline$n=5 \times 12$ & Placebo & $\begin{array}{l}\text { Diazepam } \\
15 \mathrm{mg}\end{array}$ & $\begin{array}{l}\text { Diazepam } \\
20 \mathrm{mg}\end{array}$ & $\begin{array}{l}\text { Lorazepam } \\
1.75 \mathrm{mg}\end{array}$ & $\begin{array}{l}\text { Lorazepam } \\
2.5 \mathrm{mg}\end{array}$ \\
\hline \multicolumn{6}{|l|}{ Free recall } \\
\hline $\mathrm{N}^{\circ}$ of words & $5.3 \pm 3.0$ & $2.5^{\mathrm{a}} \pm 1.7$ & $2.1^{\mathrm{a}} \pm 1.8$ & $2.2^{a} \pm 1.7$ & \pm 0.9 \\
\hline \multicolumn{6}{|c|}{ Word completion } \\
\hline \multicolumn{6}{|c|}{$\mathrm{N}^{\circ}$ of words } \\
\hline $\begin{array}{l}\text { New words } \\
\text { Old words } \\
\text { Old-new }\end{array}$ & $\begin{array}{l}2.4 \pm 1.2 \\
6.7 \pm 3.2 \\
4.25 \pm 2.8\end{array}$ & $\begin{array}{l}3.1 \pm 3.2 \\
5.6 \pm 2.6 \\
2.5 \pm 2.6\end{array}$ & $\begin{array}{l}3.9 \pm 1.6 \\
6.7 \pm 2.9 \\
2.75 \pm 4.0\end{array}$ & $\begin{array}{l}2.4 \pm 1.8 \\
3.7 \pm 2.0 \\
1.3 \pm 3.1\end{array}$ & $\begin{array}{l}2.1 \pm 1.5 \\
2.5^{\mathrm{a}, \mathrm{b}} \pm 1.7 \\
0.4^{\mathrm{a}} \pm 2.0\end{array}$ \\
\hline
\end{tabular}

Values are means $\pm \mathrm{SD}$

${ }^{a}$ Performance significantly different from that of the placebo group $(P<0.05)$

b Performance significantly different form that of the diazepam $15 \mathrm{mg}$ and $20 \mathrm{mg}$ groups $(P<0.05)$

( $t$-tests; $P$ values corrected according to the Bonferroni probabilities)

old-new: Difference between the number of old and new words successfully completed 
test), diazepam $15 \mathrm{mg}(P<0.0001)$, diazepam $20 \mathrm{mg}$ $(P<0.01)$ and lorazepam $2.5 \mathrm{mg}(P<0.05)$ groups. The results were marginally significant in the lorazepam $1.75 \mathrm{mg}$ group $(P=0.06)$. The most important cell contribution to $\mathrm{chi}^{2}$ was that of words which were completed successfully and then recalled. In other words, the conditional probability of recall, given successful completion, was higher than the simple probability of successful completion (placebo group: 0.50 versus 0.22 , diazepam $15 \mathrm{mg}: 0.47$ versus 0.19 , diazepam $20 \mathrm{mg}: 0.48$ versus 0.22 , lorazepam $2.5 \mathrm{mg}$ : 0.30 versus 0.08 , lorazepam $1.75 \mathrm{mg}: 0.26$ versus 0.125 . These results showed a stochastic dependence between the two tests.

\section{Picture-completion task}

Mean picture-completion performances are shown in Table 3. The identification thresholds of new pictures did not vary significantly across groups $[F(4,55)=2.03]$. The identification thresholds of old pictures and the savings were analysed using a two-way ANOVA, with drugs as a between-subject factor, and condition (complete versus fragmented) as a within-subject factor. An ANOVA carried out on savings yielded a significant main effect of drugs $[F(4,55)=14.8, P<0.0001]$, a significant main effect of condition $[F(1,55)=64.1, P<0.0001)$ and a significant interaction between drugs and condition $[F(4,55)=3.07, P<0.05]$. An ANOVA carried out on the identification thresholds of old pictures yielded similar results. Follow up analyses indicated that, as expected, performances were significantly better in the fragmented than in the complete condition. In the complete condition, lorazepam $1.75 \mathrm{mg}$ induced a significant impairment of the identification thresholds of old pictures, as compared to placebo and diazepam $15 \mathrm{mg}$ and $20 \mathrm{mg}$, and a significant impairment of savings, as compared to diazepam $15 \mathrm{mg}$. In the fragmented condition, lorazepam $1.75 \mathrm{mg}$ induced a significant impairment of the identification thresholds of old pictures and of savings, as compared to placebo. Lorazepam $2.5 \mathrm{mg}$ significantly decreased performance (whether expressed as identification thresholds of old pictures or as savings) as compared to placebo and diazepam 15 and $20 \mathrm{mg}$ in both conditions, virtually no more savings being observed in the complete condition. The interaction between drugs and condition was probably due to the fact that the effect of diazepam on performance depended on whether pictures had previously been presented complete or fragmented. Whereas diazepam did not impair performance in the complete condition, a deficit was observed in the fragmented condition, which was significant at the $15 \mathrm{mg}$ dose (identification thresholds of old pictures) and at the $20 \mathrm{mg}$ dose (identification thresholds of old pictures and savings), compared to placebo.

\section{Digit symbol substitution task}

Performance on this test was significantly reduced in the lorazepam $2.5 \mathrm{mg}$ group, but not in the other groups $[F(4,55)=5.51, P<0.001]$, (Table 4).

\section{Gottschaldt's hidden figures task}

This task showed a significant drug effect, whether performance was measured by the number of the figures correctly outlined $[F(4,55)=3.21, P<0.02]$ or by the time required to perform the task $[F(4,55)=7.82, P<0.0001]$. Performance diminished in the four active groups, but the difference was only significant for the lorazepam $1.75 \mathrm{mg}$ group (time required to perform the task) and for the lorazepam $2.5 \mathrm{mg}$ group (time required to perform the task and number of the figures correctly outlined), (Table 4).

\section{Digit span task}

No significant drug effect was observed $[F(4,55)=1.97]$.
Table 3. Effects of placebo, diazepam and lorazepam on identification thresholds and savings in the picture-fragment completion task

\begin{tabular}{|c|c|c|c|c|c|}
\hline$n=5 \times 12$ & Placebo & $\begin{array}{l}\text { Diazepam } \\
15 \mathrm{mg}\end{array}$ & $\begin{array}{l}\text { Diazepam } \\
20 \mathrm{mg}\end{array}$ & $\begin{array}{l}\text { Lorazepam } \\
1.75 \mathrm{mg}\end{array}$ & $\begin{array}{l}\text { Lorazepam } \\
2.5 \mathrm{mg}\end{array}$ \\
\hline \multicolumn{6}{|l|}{ Identification thresholds } \\
\hline New pictures & $5.2 \pm 0.6$ & $5.6 \pm 0.3$ & $5.5 \pm 0.3$ & \pm 0.5 & $5.7 \pm 0.5$ \\
\hline \multicolumn{6}{|l|}{ Old pictures } \\
\hline Complete condition & $4.1 \pm 0.9$ & $4.2 \pm 0.7$ & $4.4 \pm 0.7$ & $5.2^{\mathrm{abc}} \pm 0.7$ & $5.9^{a b c} \pm 0.5$ \\
\hline Fragmented condition & $2.9 \pm 0.6$ & $3.7^{\mathrm{a}} \pm 0.6$ & $4.1^{\mathrm{a}} \pm 0.7$ & $4.4^{\mathrm{a}} \pm 0.5$ & $5.0^{\mathrm{abc}} \pm 0.8$ \\
\hline \multicolumn{6}{|l|}{$\begin{array}{l}\text { Savings } \\
\text { (old-new) }\end{array}$} \\
\hline Complete condition & $1.1 \pm 0.7$ & $1.4 \pm 0.5$ & $1.2 \pm 0.6$ & $0.4^{b} \pm 0.7$ & $-0.2^{\mathrm{abc}} \pm 0.7$ \\
\hline Fragmented condition & $2.3 \pm 0.6$ & $1.9 \pm 0.5$ & $1.4^{\mathrm{a}} \pm 0.7$ & $1.2^{\mathrm{a}} \pm 0.6$ & $0.7^{\mathrm{abc}} \pm 0.7$ \\
\hline \multicolumn{6}{|c|}{$\begin{array}{l}\text { Values are means } \pm \text { SD } \\
\text { a Performance significantly different from that of the placebo group }(P<0.05) \\
\text { b Performance significantly different from that of the diazepam } 15 \mathrm{mg} \text { group }(P<0.05) \\
\text { c Performance significantly different from that of the diazepam } 20 \mathrm{mg} \text { group }(P<0.05) \\
\text { ( } t \text {-tests; } P \text { values corrected according to the Bonferroni probabilities) } \\
\text { Savings: Difference between the identification thresholds of old and new pictures }\end{array}$} \\
\hline
\end{tabular}


Table 4. Effects of diazepam, lorazepam and placebo on DSST, Gottschaldt's hidden figures, digit span, word-generation performances and on self-ratings of sedation

\begin{tabular}{|c|c|c|c|c|c|}
\hline$n=5 \times 12$ & Placebo & $\begin{array}{l}\text { Diazepam } \\
15 \mathrm{mg}\end{array}$ & $\begin{array}{l}\text { Diazepam } \\
20 \mathrm{mg}\end{array}$ & $\begin{array}{l}\text { Lorazepam } \\
1.75 \mathrm{mg}\end{array}$ & $\begin{array}{l}\text { Lorazepam } \\
2.5 \mathrm{mg}\end{array}$ \\
\hline $\begin{array}{l}\text { Digit symbol substitution test } \\
\text { (standard score) }\end{array}$ & $13.8 \pm 1.7$ & $12.0 \pm 2.6$ & $12.6 \pm 1.9$ & $11.7 \pm 1.6$ & $9.9^{\mathrm{a}} \pm 2.6$ \\
\hline \multicolumn{6}{|l|}{ Gottschaldt's hidden figures task } \\
\hline Time (s) & $207 \pm 46$ & $260 \pm 43$ & $253 \pm 77$ & $342^{\mathrm{a}} \pm 90$ & $355^{\mathrm{ab}} \pm 112$ \\
\hline Figures correctly outlined $\left(\mathrm{n}^{\circ}\right)$ & $32.7 \pm 1.2$ & $31.6 \pm 1.7$ & $31.25 \pm 2.1$ & $30.9 \pm 1.9$ & $30.0^{\mathrm{a}} \pm 2.3$ \\
\hline \multicolumn{6}{|l|}{ Generation tasks } \\
\hline Category generation & $19.1 \pm 3.6$ & $18.6 \pm 4.8$ & $17.2 \pm 4.4$ & $16.8 \pm 4.2$ & $18.2 \pm 5.0$ \\
\hline Letter generation & $3.2 \pm 2.1$ & $4.0 \pm 1.6$ & $2.7 \pm 1.4$ & $3.2 \pm 1.4$ & $2.6 \pm 3.3$ \\
\hline Self-ratings of sedation (mm) & $34.6 \pm 16.6$ & $58.5^{\mathrm{a}} \pm 18.4$ & $48.7 \pm 15.7$ & $50.25 \pm 15.0$ & $58.9^{\mathrm{a}} \pm 15.4$ \\
\hline
\end{tabular}

Values are means $\pm \mathrm{SD}$

a Performance significantly different from that of the placebo group $(P<0.05)$

\section{Category- and letter-generation tasks}

No significant drug effect was observed in the categorygeneration task $[F(4,55)=0.55]$ or in the letter-generation task $[F(4,55)=1.44]$, $($ Table 4$)$.

\section{Self-ratings of sedation}

Self-ratings of sedation showed a significant drug effect $\left[F_{s}(4,55)=4.45, P<0.01\right]$. Subjects experienced a substantial sedative effect in the four active groups, the differences being significant in the diazepam $15 \mathrm{mg}$ group and in the lorazepam $2.5 \mathrm{mg}$ group (Table 4).

\section{ANCOVAs}

ANCOVAs were carried out on word-completion performance and on picture-completion performance (identification thresholds of old pictures and savings in both conditions), with free-recall, digit symbol substitution, Gottschaldt's task performance and self-rated sedation as covariates. There was a significant influence, due to lorazepam, of Gottschaldt's task performance (whether expressed as time required to perform the task or as number of the figures correctly oulined) on the identification thresholds of old pictures in both conditions $\left(F_{S}>5.13, P_{S}<0.05\right)$. There was also a significant influence of self-rated sedation on the identification thresholds of old pictures in the fragmented condition $(F=5.21, P<0.05)$; this influence was due to the four active groups. Finally, there was a significant influence, due to lorazepam, of digit symbol substitution performance on Gottschaldt's task performance $(F=26.0 ; P<0.0001)$.

\section{Awareness questionnaires}

The number of subjects who were aware of a relationship between the study and test phases of the word- b Performance significantly different from that of the diazepam 15 and $20 \mathrm{mg}$ groups $(P<0.05)$

( $t$-tests; $P$ values corrected according to the Bonferroni probabilities)

completion task was higher in the placebo group (11 out of 12) than in the other groups (7 out of 12 in the diazepam $15 \mathrm{mg}$ group and 5 out of 12 in each of the remaining groups). All subjects were aware of the nature of the picture-completion task, with the exception of one subject in the lorazepam $1.75 \mathrm{mg}$ group and two subjects in the lorazepam $2.5 \mathrm{mg}$ group.

\section{Discussion}

This study indicates that diazepam and lorazepam have differential amnestic effects. As previously demonstrated (Fang et al. 1987; Danion et al. 1989, 1990), diazepam impaired free recall but spared word completion, therefore inducing a dissociation between explicit and implicit memory. Lorazepam impaired free-recall as well as word-completion performance, as measured by the number of old words successfully completed: a deleterious effect was observed at the $1.75 \mathrm{mg}$ dose and was reliable at the $2.5 \mathrm{mg}$ dose, in comparison to performance in the placebo and diazepam groups. The analysis of implicit performance, as measured by the difference between the number of old and new words successfully completed, supports the same interpretation, even though the differential effects of the two benzodiazepines were not significant. The absence of significant changes in the number of new words successfully completed, in conjunction with intact performance in the category- and lettergeneration tasks, indicates that lorazepam-induced impairment of word completion cannot be explained by a disturbance of lexical access.

Previous studies which demonstrated that lorazepam impairs word-completion performance (Brown et al. 1989; Danion et al. 1992) have been unable to determine whether this effect was task-dependent or reflected a genuinely deleterious effect on lexical priming per se, since they did not include other priming tasks. A picturecompletion task, assessing a more perceptual priming, was included in this study to investigate this issue. A 
deleterious, dose-dependent lorazepam effect was once more found in both complete and fragmented conditions of this task, virtually no savings being observed with the highest dose. Despite the fact that the two tests differed in terms of intentional (word-completion test) or incidental (picture-completion test) instructions, both were impaired by the drug. These results argue against the hypothesis that the lorazepam effect is task-dependent, and strongly support the notion that it is the priming effect per se, whether lexical or perceptual, which is impaired by the drug.

The diazepam effect in the picture-completion task depended on whether pictures were previously presented complete or fragmented. No deleterious effect was observed in the complete condition, but performance was lower in the fragmented condition. This pattern of results can best be interpreted within the framework of the perceptual closure hypothesis which has been recently renewed by Snodgrass and Feenan (1990). According to this framework, the presentation at study of fragmented pictures results in enhanced savings in the subsequent picture-identification task which can be accounted for by the experience of perceptual closure, i.e., filling in gaps in contours of fragmented pictures so as to perceive the most meaningful forms that circumstances permit. If this experience occurred during the study phase, it would involve a reorganisation of the processes of perceiving a particular picture, such that perceptual closure would be achieved at test with less information than before the reorganization. It can be suggested that a deleterious diazepam effect is observed in the fragmented condition but not in the complete condition because the former represents a more potent paradigm for revealing a deleterious drug effect on perceptual savings. However, it is unclear whether the deficit induced by diazepam in the fragmented condition is specific, i.e. reflects a true decrease in perceptual priming, or non-specific, i.e. is the expression of a deleterious effect of diazepam on other kinds of processes, such as those involved in conceptual priming, which is impaired by diazepam (Fang et al. 1987) and lorazepam (Brown et al. 1989). In particular, it is possible that the sedation induced by diazepam may have played a role in this deficit; this is supported by an ANCOVA which revealed a significant influence of selfrated sedation on performance in the fragmented condition of the picture-completion test. According to this view, the amnestic effects of diazepam and lorazepam would differ qualitatively rather than quantitatively. It is not possible to establish on the basis of this study whether the diazepam-induced deficit is specific or not. But whatever the correct explanation, it must be emphasized that the deleterious diazepam effect is far less pronounced than the lorazepam effect, thus providing strong evidence for differential amnesic effects in both tests of implicit memory.

Since memory and the cognitive effects of benzodiazepines are dose dependent, it could be claimed that the differential effects of diazepam and lorazepam are explained by the selection of non equipotential doses of the drugs. The doses were chosen to provoke an explicit memory deficit of comparable magnitude. However, it is difficult to determine such a correspondence since direct comparisons between the two drugs are scarce and inconsistent (Dundee et al. 1979; Kothary et al. 1981). The results of the free-recall test suggest that lorazepam $2.5 \mathrm{mg}$ affected slightly more explicit memory than diazepam $20 \mathrm{mg}$, although there was no significant difference between the active groups. The same point can be made with regard to the digit symbol substitution test and the Gottschaldt's hidden figures test. These results could lead to the conclusion that lorazepam exhibited differential effects in priming tasks only because the $2.5 \mathrm{mg}$ dose was more potent than the 15 and $20 \mathrm{mg}$ doses of diazepam. However, this seems unlikely for two reasons. Firstly, lorazepam $1.75 \mathrm{mg}$, which induced a similar impairment of explicit memory as diazepam $15 \mathrm{mg}$, clearly differs from diazepam as regards its effects on implicit tasks. Secondly, to equalise explicit memory performance in
Table 5. Effects of diazepam and lorazepam on word-completion and picturecompletion performance of subjects with free recall $\leq 1$

\begin{tabular}{|c|c|c|c|c|}
\hline & $\begin{array}{l}\text { Diazepam } \\
(n=8)\end{array}$ & $\begin{array}{l}\text { Lorazepam } \\
(n=13)\end{array}$ & $t$ & $P$ \\
\hline $\begin{array}{l}\text { Free recall } \\
\left(\mathrm{N}^{\circ} \text { of words }\right)\end{array}$ & $0.38 \pm 0.47$ & $0.38 \pm 0.52$ & 0 & NS \\
\hline \multicolumn{5}{|l|}{$\begin{array}{l}\text { Word completion } \\
\left(\mathrm{N}^{\circ} \text { of words }\right)\end{array}$} \\
\hline $\begin{array}{l}\text { Old words } \\
\text { Old-new }\end{array}$ & $\begin{array}{l}6.25 \pm 3.70 \\
2.25 \pm 4.10\end{array}$ & $\begin{array}{l}2.77 \pm 1.69 \\
1.23 \pm 1.69\end{array}$ & $\begin{array}{l}-2.48 \\
-0.67\end{array}$ & $\begin{array}{c}<0.05 \\
\text { NS }\end{array}$ \\
\hline \multicolumn{5}{|l|}{$\begin{array}{l}\text { Picture completion } \\
\text { Identification thresholds }\end{array}$} \\
\hline $\begin{array}{l}\text { Complete condition } \\
\text { Fragmented condition }\end{array}$ & $\begin{array}{l}4.21 \pm 0.81 \\
3.96 \pm 0.45\end{array}$ & $\begin{array}{l}5.79 \pm 0.51 \\
5.06 \pm 0.75\end{array}$ & $\begin{array}{l}5.46 \\
3.71\end{array}$ & $\begin{array}{l}<0.001 \\
<0.01\end{array}$ \\
\hline \multicolumn{5}{|l|}{ Savings } \\
\hline $\begin{array}{l}\text { Complete condition } \\
\text { Fragmented condition }\end{array}$ & $\begin{array}{l}1.16 \pm 0.75 \\
1.41 \pm 0.68\end{array}$ & $\begin{array}{l}0.03 \pm 0.60 \\
0.76 \pm 0.59\end{array}$ & $\begin{array}{l}3.60 \\
2.31\end{array}$ & $\begin{array}{c}<0.01 \\
\text { NS }\end{array}$ \\
\hline
\end{tabular}

Values are means $\pm \mathrm{SD}, t$-tests

Old-new: difference between the number of old and new words successfully completed Savings: difference between the identification thresholds of old and new pictures 
active groups, two subgroups of diazepam- and lorazepam-treated subjects who were unable to recall more than one item were constituted. In conditions where the explicit memory deficit was similar, the patterns of implicit memory dysfunction of the two subgroups were identical to those observed in the whole groups (Table 5).

The differential amnestic effects of diazepam and lorazepam are unlikely to be explained by changes in shortterm memory or recording skills, as suggested by the absence of any significant influence of digit symbol substitution performance on implicit memory performance. However, there was a significant influence, due to lorazepam, on performance in both conditions of the picture-completion task when Gottschaldt's test performance was taken as a covariate. The significance of the impairment of this test, which was intended to assess the ability to perceive visual information, is unclear. The deficit was probably unspecific, since a significant influence on Gottschaldt's test performance was found in an ANCOVA using digit symbol substitution performance as a covariate. In addition, the identification of new pictures in the picture-completion test was not impaired by the drugs, suggesting that the ability to perceive visual information remained intact. The differential effects of the two benzodiazepines cannot be accounted for by differences in awareness of the nature of the implicit tasks, since the number of subjects who were aware of a relationship between the study and test phases of the word- and picture-completion tests was similar for the four active groups.

As discussed by Richardson-Klavehn and Bjork (1988), the fact that a manipulated variable induces similar effects on explicit and implicit tests might mean either that the variable affects a form of memory that is contributing to performance in both tests, or that this variable has similar effects on two different forms of memory. One way to decide between these interpretations is to look for a stochastic dependence. The demonstration of a dependence would argue in favour of the first interpretation, whereas its absence would support the second. Accordingly, these results, which demonstrated a stochastic dependence between free-recall and word-completion in the lorazepam $2.5 \mathrm{mg}$ group, could be taken as evidence that only one form of memory was impaired by the drug. However, this seems unlikely, for two reasons. Firstly, the stochastic dependence was not specific to the lorazepam group, and might be attributed to an inter-test bias, due to the fact that the successful completion of a word in the implicit test acts as a second study trial and boosts subsequent explicit memory performance (Tulving et al. 1982; Shimamura 1985; Danion et al. 1989); this bias across tests prevents the establishment of stochastic dependence, even if explicit and implicit memory are independent. Secondly, the absence of a significant correlation between free-recall and word-completion performance, together with the diazepam-induced dissociation between explicit memory and priming, and with the previously demonstrated dissociations induced by various pathological and experimental situations, all argue in favour of two psychobiologically distinct forms of memory.
This study offers consistent evidence that two benzodiazepines have differential amnestic effects. Similar differences have been reported in a review by Curran (1991), quoting an unpublished study that compared the effects of oxazepam and lorazepam on a word-stem completion task. Such differential effects, observed with drugs which belong to the very homogeneous pharmacological class of full agonists of benzodiazepine receptors, call for replication with these and other benzodiazepines, and require further investigations, if they are to be explained. It is well known that benzodiazepines exhibit a cerebral cortex fixation, which is highest in the frontal and occipital areas (Sieghart et al. 1985; Trifiletti et al. 1987). Since lexical and perceptual priming is probably dependent on the temporo-parietal and occipital cortical areas respectively (Keane et al. 1991), it can be suggested that a differential cortical distribution of diazepam and lorazepam could account for their differing amnestic effects. An investigation of the cerebral fixation of the two drugs using positron emission tomography, as has been recently undertaken with flumazenil (Abadie et al. 1991), could offer some clues to help resolve this issue.

The clinical implications of the differential amnestic effects of diazepam and lorazepam remain to be elucidated. Although priming is probably a ubiquitously occuring phenomenon in every day life, the consequences of its impairment on people's ability to function efficiently is unknown.

Acknowledgement. This research was supported by a grant from Produits Roche, Neuilly-Sur-Seine, France.

\section{References}

Abadie P, Bisserbe JC, Boulenger JP, Travere JM, Barre L, Petit MC, Zarifian E, Baron JC (1991) Central benzodiazepine receptors: quantitative positron emission tomography study in healthy subjects and anxious patients. In: Briley P, File SE (eds) New concepts in anxiety. Macmillan, London

Ameer B, Greenblatt DJ (1981) Lorazepam: a review of its clinical pharmacological properties and therapeutic use. Drugs $21: 161-200$

Bowers JS, Schacter DL (1990) Implicit memory and test awareness. J Exp Psychol: [Learn Mem Cogn] 16:404-416

Brandt AL, Oakes FD (1965) Preanesthesia medication: doubleblind study of a new drug, diazepam. Anesth Analg 44:125

Brown J, Lewis V, Brown M, Horn G, Bowes JB (1982) A comparison between transient amnesias induced by two drugs (diazepam and lorazepam) and amnesia of organic origin. Neuropsychologia $20: 55-70$

Brown MW, Brown J, Bowes JB (1989) Absence of priming coupled with substantially preserved recognition in lorazepam-induced amnesia. Q J Exp Psychol 41A: 599-617

Brown SS, Dundee JW (1968) Clinical studies of induction agents XXV: diazepam. Br J Anaesth 40:108-112

Cermak LS, Talbot N, Chandler K, Wolbarst LR (1985) The perceptual priming phenomenon in amnesia. Neuropsychologia $29: 615-622$

Clark EO, Glanzer M, Turndorf H (1979) The pattern of memory loss resulting from intravenously administered diazepam. Arch Neurol 36:296-300

Clarke PRF, Eccersley PS, Frisby JP, Thornton JA (1970) The amnesic effect of diazepam (Valium). Br J Anaesth 42: 690-697 
Cochran WG, Cox GM (1957) Experimental designs, 2nd edn. Wiley, New York

Curran HV (1991) Benzodiazepines, memory and mood: a review. Psychopharmacology 105: 1-8

Danion JM, Zimmermann MA, Willard-Schroeder D, Grangé D, Singer L (1989) Diazepam induces a dissociation between explicit and implicit memory. Psychopharmacology 99:238-243

Danion JM, Zimmermann MA, Willard-Schroeder D, Grangé D, Welsch M, Imbs JL, Singer L (1990) Effects of scopolamine, trimipramine and diazepam on explicit memory and repetition priming in healthy volunteers. Psychopharmacology 102:422-424

Danion JM, Peretti S, Grangé D, Bilik M, Imbs JL, Singer L (1992) Effects of chlorpromazine and lorazepam on explicit memory, repetition priming and cognitive skill learning in healthy volunteers. Psychopharmacology 108:345-351

Dundee JW, McGowan WAW, Lilburn JK, McKay AC, Hegarty JE (1979) Comparison of the actions of diazepam and lorazepam. Br J Anaesth 51:439-446

Fang JC, Hinrichs JV, Ghoneim MM (1987) Diazepam and memory: evidence for spared memory function. Pharmacol Biochem. Behav 28:347-352

Ghoneim MM, Mewaldt SP (1975) Effects of diazepam and scopolamine on storage, retrieval and organizational processes in memory. Psychopharmacology 44:257-262

Ghoneim MM, Hinrichs JV, Mewaldt SP (1984) Dose-response analysis of the behavioural effects of diazepam: I. learning and memory. Psychopharmacology 82:291-295

Gottschaldt K (1928) Uber den Einfluss der'Erfahrung auf die Wahrnehmung von Figuren. Psychologische Forschung $8: 18-317$

Graf P, Schacter DL (1985) Implicit and explicit memory for new associations in normal and amnesic subjects. J Exp Psychol [Learn Mem Cogn] 11:501-518

Graf P, Squire LR, Mandler G (1984) The information that amnesic patients do not forget. J Exp Psychol [Learn Mem Cogn] $10: 164-178$

Juilland A, Brodin D, Davidovitch C (1970) Dictionnaire de la fréquence des mots français. Mouton, Paris

Keane ME, Gabrieli JDE, Fennema AC, Growdon JH, Corkin S (1991) Evidence for a dissociation between perceptual and conceptual priming in Alzheimer's disease. Behav Neurosci $2: 326-342$
Kothary SP, Brown ACD, Pandit UA, Samra SK, Pandit SK (1981) Time course of antirecall effect of diazepam and lorazepam following oral administration. Anesthesiology 55:641-644

Lister R (1985) The amnesic action of benzodiazepines in man. Neurosci Behav Rev 9:87-94

Lister R (1991) The effects of benzodiazepines and 5-HT $\mathrm{HA}_{1 \mathrm{~A}}$ agonist on learning and memory. In: Rodgers RJ, Cooper SJ (eds) 5-HT ${ }_{1 \mathrm{~A}}$ agonists, 5-- $\mathrm{HT}_{3}$ antagonists and benzodiazepines: their comparative behavioural pharmacology. Wiley, New York

Mandelli M, Tognoni G, Garattini S (1978) Clinical pharmacokinetics of diazepam. Clin Pharmacokinet 3:72-91

Moscovitch M, Winocur G, McLaghan D (1986) Memory as assessed by recognition and reading time in normal and memoryimpaired people with Alzheimer's disease and other related disorders. J Exp Psychol Gen 115:331-347

Richardson-Klavehn A, Bjork RA (1988) Measures of memory. Annu Rev Psychol 39:475-543

Shimamura AP (1985) Problems with the finding of stochastic independence as evidence for multiple memory systems. Bull Psychon Soc 23:506-508

Sieghart W, Eichinger A, Riederer P, Jellinger K (1985) Comparison of benzodiazepine receptor binding in membranes from human or rat brain. Neuropharmacology 24:751-759

Snodgrass JA, Feenan K (1990) Priming effects in picture fragment completion: support for the perceptual closure hypothesis. J Exp Psychol Gen 119:276-296

Snodgrass JA, Smith B, Feenan K (1987) Fragmenting pictures on the Apple Macintosh computer for experimental and clinical applications. Behav Res Methods Instrum Comput 19:270-274

Trifiletti RR, Snowman AM, Whitehouse PJ, Marcus KA, Snyder SH (1987) Huntington's disease: increased number and altered regulation of benzodiazepine receptor complexes in frontal cerebral cortex. Neurology 37:916-922

Tulving E, Schacter DL (1990) Priming and human memory systems. Science 247:301-306

Tulving E, Schacter DL, Stark HA (1982) Priming effects in wordfragment completion are independent of recognition memory. J Exp Psychol [Learn Mem Cogn] 8:336-342

Warrington EK, Weiskrantz L (1970) Amnesic syndrome: consolidation or retrieval? Nature 228:628-630

Wechsler Adult Intelligence Scale - Revised (1981) The Psychological Corporation, New York. Traduction et adaptation françaises (1989). Les Editions du Centre de Psychologie Appliquée, Paris 